\title{
The potential of the internet as a medium to encourage and discourage youth tobacco use
}

\section{K M RibisI}

The internet is fast becoming a new battleground between tobacco control advocates and pro-tobacco forces, and this new media will certainly have a greater impact on tobacco use behaviour in the future. This paper reviews how the internet can encourage youth smoking by providing youth access to tobacco products and offering content that glamorises smoking lifestyle and culture, particularly in hundreds of websites and chat rooms. These sites feature pictures of celebrity smokers, provide information about smoking in movies, and provide smoking advice to teen smokers. In contrast, youth smoking is discouraged on online grassroots advocacy and countermarketing websites. Although these strategies show promise, more research is needed to evaluate their impact. Recommendations are made for future research to study pro-smoking internet content and ways to counteract it, as well as to monitor the online activities of the tobacco companies. Finally, some of the challenges in addressing tobacco related internet content are discussed.

Correspondence to Kurt M Ribisl, PhD, Department of Health Behavior and Health Education, School of Public Health, University of North

Carolina at Chapel Hill, Chapel Hill, NC 27599-7440, USA kurt_ribisl@unc.edu
$\mathrm{T}$ he explosive growth of the internet has created unprecedented opportunities and challenges for the field of tobacco control research and practice. As of September 2001, 143 million Americans (about 54\% of the US population) were using the internet. ${ }^{1}$ This is a substantial increase from 116.5 million Americans online in August 2000 and 84.6 million online in December 1998.

Today's young people have been called the first "Net generation" or "Digital generation," given their fondness for new information technologies and the internet. In fact, by age 10, young people are more likely to use the internet than adults at any age beyond $25 .{ }^{1}$ Nearly two thirds (65.4\%) of 10-13 year olds and more than three quarters (75.6\%) of 14-17 year olds use the internet. In 2001, households with a school age child were more likely to have internet access (62.2\%) than were households without a school age child (53.2\%). ${ }^{1}$ Over $95 \%$ of US schools are now linked to the internet and $89 \%$ of US schools have high

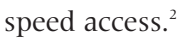

In the USA, children and teenagers use the internet primarily for schoolwork, communication, and entertainment. Among all 10-13 year olds, a very high percentage $(76.6 \%)$ used the internet for schoolwork. Other popular activities were playing games $(64.7 \%)$, emailing $(63.8 \%)$, listening to radio/watching movies (17.9\%), and visiting chat rooms (16.0\%). Among all 14-17 year olds, $86.1 \%$ used the internet for schoolwork, followed by email $(82.1 \%)$, playing games $(61.0 \%)$, visiting chat rooms $(34.2 \%)$, and listening to radio/watching movies $(26.9 \%)$. ${ }^{1}$

Although the impact of the internet on tobacco use behaviour among youth has probably been modest thus far, this form of new media will certainly have a greater impact in the future. The internet has potential as a medium for encouraging youth smoking as well as discouraging youth smoking. Neither potential has been fully realised, and the future will dictate which use has greater impact. In the tobacco industry trade journal Tobacco Reporter an article entitled "Tobacco on the web" ${ }^{\prime 3}$ made this observation:

\begin{abstract}
"For the cigarette industry, the internet has been something of a two-edged sword. On the one hand, it has provided companies with the ability to create a window to the world that publicizes their products and generates new business. On the other, it has provided a vehicle for anti-tobacco groups to organize a concerted effort to restrict or even prevent the use of tobacco." (page 64)
\end{abstract}

The internet is fast becoming a new battleground between tobacco control advocates and tobacco companies and other pro-tobacco forces. The internet may influence youth tobacco use because it provides potential access to tobacco products as well as a venue that may stimulate demand for them through advertising and promotional messages. For these reasons, it is functionally similar to a retail outlet that sells tobacco products and also features ubiquitous tobacco advertising and pro-smoking messages. On the prevention side, tobacco control activists have begun to harness the power of the internet to discourage smoking through grassroots mobilisation and countermarketing efforts. This paper examines the potential of the internet to promote smoking through providing youth access to tobacco products and offering content that glamorises smoking lifestyle and culture. Then it addresses how tobacco control advocates have used the internet to discourage smoking, and some of the challenges and opportunities in addressing smoking related internet content. In a separate paper in this volume, Mermelstein ${ }^{4}$ has addressed the issue of how the internet can be used to deliver tobacco use cessation interventions for youth.

\section{YOUTH ACCESS TO TOBACCO ON THE INTERNET}

The emergence of websites selling tobacco products has created several policy challenges for government and public health officials, including 


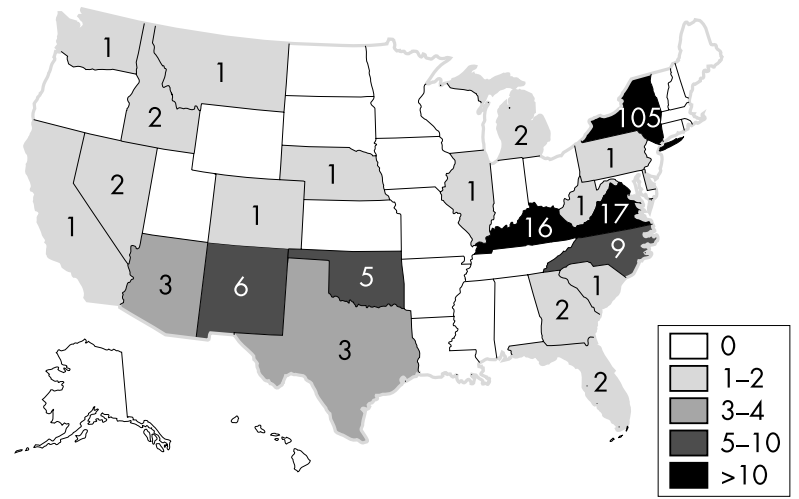

Figure 1 Location of internet cigarette vendors in the USA, January $2002(n=195)$. State location of 10 internet vendors could not be determined.

growing concern that internet vendors might be selling tobacco products to minors. ${ }^{56}$ This section documents the growth in the number of internet cigarette vendors, examines whether they sell cigarettes to minors, reviews survey data on whether youth are buying cigarettes online, and concludes with recommendations for limiting youth access to tobacco products on the internet.

\section{Internet tobacco vendors}

The Center for Media Education (CME) issued a report in 1997 that examined websites advertising and selling alcohol and tobacco products. ${ }^{7}$ Relying on search engines, links offered from other websites, and trade publication articles, the CME identified 13 internet vendors that sold cigarettes. Three years later, a study by Ribisl and colleagues ${ }^{8}$ estimated the number and geographic location of websites selling cigarettes in the USA, and examined their sales and marketing practices. Comprehensive internet based searches were conducted between November 1999 and January 2000 using four keyword terms (cheap cigarette, discount cigarette, mail order cigarette, tax-free cigarette) and five popular internet search engines (www.altavista.com, www.excite.com, www. go.com, www.lycos.com, www.yahoo.com), supplemented by sites listed on a directory of internet cigarette vendors that was mentioned in a magazine article.' Over 1800 sites were examined to identify 88 internet cigarette vendors operating in the USA. Internet cigarette vendors were located in 23 states, and 49 of the 88 sites were located on Indian reservations. A follow up study in January 2002 using a similar methodology by the same team identified 195 internet cigarette vendors in the USA. Figure 1 shows the geographic distribution of these internet vendors. Similar to the January 2000 study, the majority of internet vendors were located in New York State. Nearly all of the New York vendors were located in the western part of the state on Indian reservations.

Several reasons may explain the more than doubling of the number of internet cigarette vendors over the past two years. First, a greater proportion of the US population now has internet access; over two million Americans become new internet users each month. ${ }^{1}$ Second, higher cigarette prices due to increased state excise taxes has fueled demand for cheaper cigarettes online. ${ }^{10}{ }^{11}$ Finally, as more Americans (and smokers) become comfortable with purchasing products online, the number of e-commerce sites is likely to continue growing.

Similar to the way that many retail outlets sell different types of tobacco products, the study of 88 websites that sold cigarettes found that they also sold other tobacco products, such as cigars $(42.0 \%$ of sites), smokeless tobacco $(38.6 \%)$, clove cigarettes $(18.2 \%)$, and bidis $(8.0 \%) .{ }^{8}$ There is only one study that has examined the sales practices of internet cigar vendors. Malone and colleagues ${ }^{12}$ identified 108 vendors out of a larger sample of 141 cigar marketing websites in early 1998. The authors identified these sites by examining the links listed on two popular cigar website portals that were found on www.excite.com using the search string "cigar links". A follow up study to monitor changes in the number of cigar vendors and their sales practices appears warranted. In addition, studies should also be undertaken to monitor online marketing and sales of novel tobacco products (for example, bidis and kreteks) and potentially reduced exposure products (for example, RJ Reynold's Eclipse, Vector Tobacco's Omni, and Star Scientific's Ariva).

\section{Sales practices of internet tobacco vendors}

Internet cigarette and cigar vendors do not appear to be taking adequate precautions to prevent tobacco sales to minors. The 1997 report by CME concluded that few internet vendors asked for the buyer's age, and those that did had no mechanism to verify the buyer's reported age. ${ }^{7}$ A more recent study found that although $82 \%$ of websites selling cigarettes featured warnings that the buyer must be at least 18 years or older to purchase cigarettes, effective age verification procedures were practically non-existent. ${ }^{6}$ The most common age verification procedure was self reporting of age, such as providing a check box for consumers to certify that they were of legal age $(48.9 \%)$ or asking the buyer to type in their birth date $(14.8 \%)$. Only $6.8 \%$ of online vendors stated that they required photographic age verification at delivery, which is already the prevailing standard at retail outlets. ${ }^{6}$ The majority $(68.2 \%)$ of internet cigarette vendors allowed non-credit card payment methods, such as money orders or cashier's cheques, which make them potentially accessible to youth. ${ }^{8}$ A study of internet cigar vendors found that only 36 of 108 sites featured age warnings, and 35 featured non-credit payment methods. ${ }^{12}$ Thus, many internet tobacco vendors appear to have lax age verification procedures and allow payment methods readily available to youth.

Figures 2 and 3 show the website home pages of two internet cigarette vendors. Although the name Barbi's Butts (http:// barbisbutts.com) sounds like it might contain some sexually related content, it is actually an internet vendor located on the Seneca Indian Reservation in Kill Buck, New York. This site features a warning in a small font at the very bottom of the home page that mentions "We require proof of age to protect our nations [sic] youth. You must be at least 18 years of age to purchase from this web site." They note that first time orders must be accompanied by a copy of a valid driver's license. Similarly, DJ's Smoke Shop (http://www.djsmokeshop.com) is located on the Seneca Indian reservation. DJ's requires buyers to be at least $2 \mathrm{l}$ years of age and asks them to either mail a photocopy of their driver's licence or to email them a scanned copy. By requiring photographic identification, these two vendors have more stringent precautions to prevent sales to minors than the vast majority of internet cigarette vendors. However, the results of a purchase survey, which is described in the next section of this paper, reveal that even though many internet vendors claim they require proof of age before the sale, several internet vendors sold cigarettes without identification. This suggests that advertised sales practices are not always followed in practice.

It should also be noted that the web page for DJ's Smoke Shop mentioned that their cigarettes are sold without paying state excise taxes because they are on tribal land (that portion of the website was not viewable in the screen capture shown in fig 3). Tax-free cigarettes can be sold at substantially cheaper prices than those sold at stores in places with higher state cigarette excise taxes. They also mention that their sovereign status means that they do not need to abide by the Jenkins Act, ${ }^{13}$ a federal law that requires all out-of-state sales 


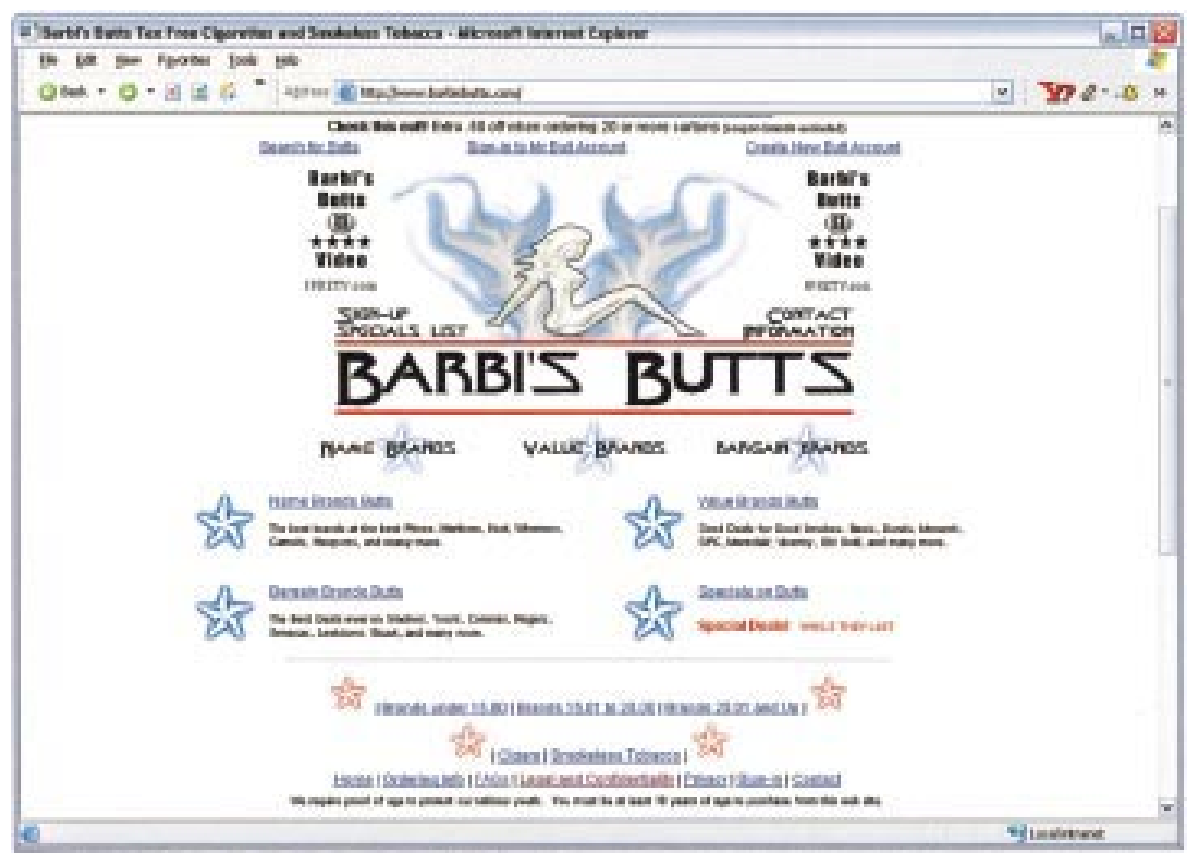

Figure 2 Home page of Barbi's Butt's tax free cigarettes and smokeless tobacco.

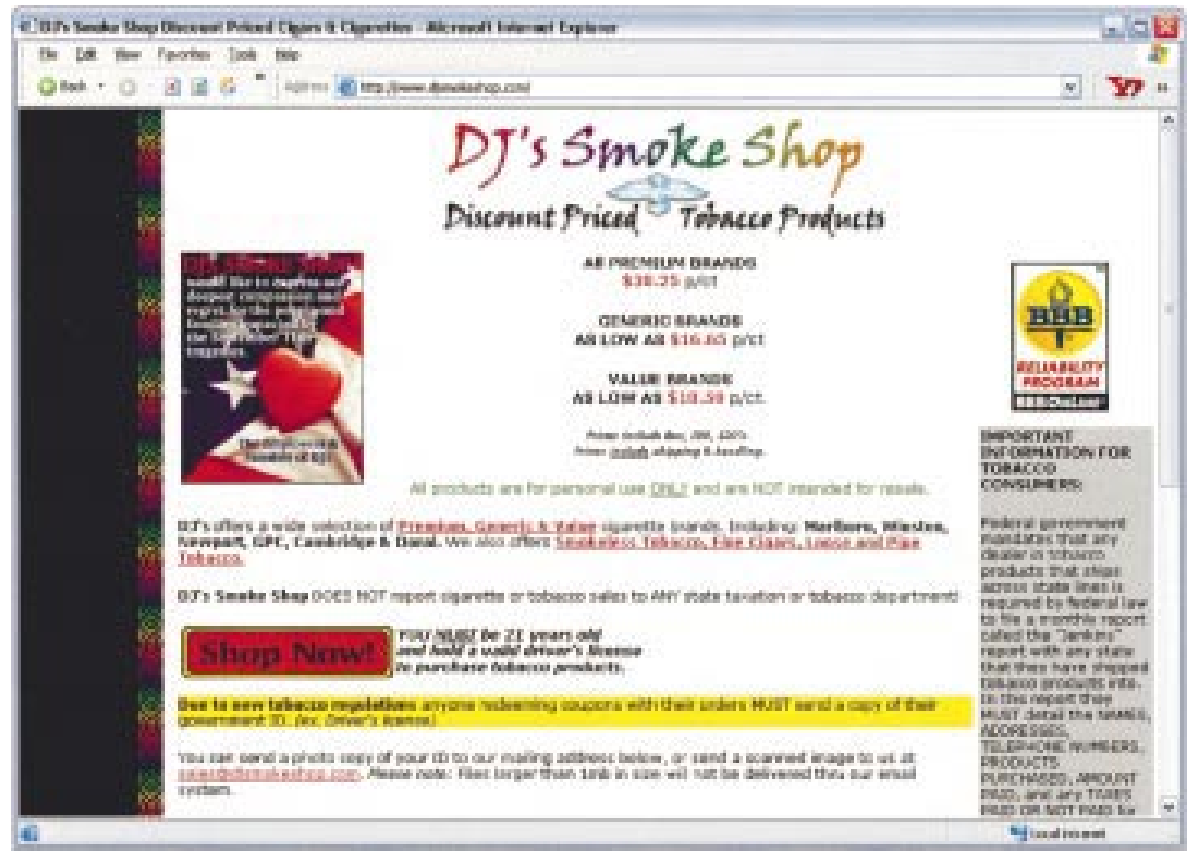

Figure 3 Home page of DJ's Smoke Shop discount priced cigars and cigarettes.

to be reported for tax purposes to the state revenue department where the buyer is located. The lack of Jenkins Act reporting undermines states' ability to monitor sales and to collect revenue from the buyers. A recent General Accounting Office Report ${ }^{14}$ found that most internet cigarette vendors are ignoring the Jenkins Act and concluded that tribal sellers are still obligated to abide by the provisions of the Jenkins Act. Relatively little is known about the extent of tax evasion owing to internet cigarette sales. One study found that there was not substantial tax evasion due to internet sales in California after the 50 cents tax increase (Proposition 10) that occurred in $1999 .{ }^{15}$ It will be important to replicate this study now that several factors have changed over the past three years: a large growth in the number of individuals using the internet, an increased number of internet vendors, and the fact that nearly half of the states in the USA have increased their state excise tax since 1999. Tax evasion from internet cigarette vendors is a serious issue because it has the potential to undermine the impact of higher cigarette prices on reduced consumption of tobacco products from both youth and adults. Moreover, states are losing valuable revenue.

Given the lax age verification standards of most internet vendors, youth could potentially order cigarettes from many of these sites by lying about their age and paying for the cigarettes with a certified cheque or money order available at most convenience stores without identification or proof of age. Additionally, teens with credit cards or debit cards with Visa/ MasterCard symbols could purchase from nearly all of the sites. One survey of 13-19 year olds found that the most common payment methods for online shopping were by parent's credit card, followed by cheque, money order, the teen's own credit card, and cash on delivery (COD) ${ }^{16}$ Although few teens have their own credit cards, there is a growing market for providing alternative payment methods for teens such as 
Visabuxx and Rocket Cash, which function in the same manner as credit cards. Thus, it is unlikely that requiring payment solely by credit card will effectively deter youth attempting to buy online.

\section{Will internet vendors sell to children?}

Although the advertised age verification procedures of internet vendors do not seem to be adequate to prevent tobacco sales to minors, these assumptions need to be tested empirically. There is ample anecdotal evidence that internet cigarette vendors sell to children, and there is one unpublished empirical study yielding the same conclusion.

According to several media reports, minors working with attorneys general in Massachusetts, Michigan, Oregon, Utah, and Washington have been successful in purchasing cigarettes from internet vendors. ${ }^{17-20}$ Children as young as 8 years old were able to purchase cigarettes and bidis (candy flavoured cigarettes from India) from internet vendors. Although these anecdotal media reports strongly suggest that youth will find easy access to tobacco via the internet, these purchases have been made from a small number of internet vendors (that is, from five and eight vendors in a couple of states), and have not employed a standardised protocol. In some instances the credit card belonged to adult member of the attorney general's staff and the internet vendors publicly defended themselves by claiming that the credit card was validated against a database of adult credit card holders.

Ribisl and colleagues ${ }^{21}$ conducted a youth tobacco purchase survey via the internet with four youth aged 11-15. Youth paid with either a money order or with a prepaid Visa card, depending on the payment method accepted by the internet vendor. The minimum age for the credit card was 13 , and real ages of the three 13-15 year olds were given on the credit card application. (One youth aged 11 did not qualify and had to use a parent's credit card.) The leading brand among youth, Marlboro, ${ }^{22}$ was ordered when it was available; if Marlboro was not available, youth ordered the cheapest brand on the website. In nine instances, proof of age was required by the vendor, and it was not submitted to test whether the internet vendor would sell without it. Youth in this study successfully received cigarettes in 76 of the 83 purchase attempts $(91.6 \%$ overall sales rate). Successful purchases occurred in 32 of 36 (88.9\%) money order purchase attempts and 44 of 47 (93.6\%) credit card purchase attempts. Four sales were refused because of lack of age identification, and five were sent anyway even though the vendor stated that ID was required. The remaining three orders were never delivered. Over $85 \%$ of the deliveries were left at the door without any age verification of the recipient. Altogether, youth received 1650 packs of cigarettes from these internet vendors. This study clearly suggests that youth who use money orders or prepaid credit cards would be able to purchase cigarettes from the majority of internet vendors. A key issue, however, is whether youth have turned to the internet to purchase cigarettes.

\section{Are kids buying cigarettes from internet vendors?}

Over $47 \%$ of American internet users have purchased something online, ${ }^{23}$ including $39 \%$ of $13-19$ year olds. ${ }^{16}$ Teens and young adults spend more money online than do adults. ${ }^{24}$ Several studies have asked youth about their sources of cigarettes and whether they purchased them via the internet. In the 2001 National Household Survey on Drug Abuse, 3.3\% of youth aged 12-17 reported purchasing cigarettes from the internet in the past month. ${ }^{25}$ Unger and colleagues ${ }^{26}$ administered a written questionnaire on tobacco related attitudes and behaviour to a representative sample of over 17000 10th and 12th grade California students during the 1999-2000 school year. Among youth under 18 years of age who were current smokers $(n=1689), 2.2 \%$ reported attempting to purchase cigarettes on the internet and $0.7 \%$ reported that the internet was the source of their last cigarette. Attempted internet purchases were more likely among younger respondents, males, frequent smokers, and respondents reporting lower perceived availability of tobacco products from retail and social sources.

In another study, ninth grade current smokers $(n=1323)$ in three western New York counties were asked about purchasing cigarettes on the internet in the 2000-2001 school year. ${ }^{27}$ A total of $2.3 \%$ of current smokers reported ever purchasing cigarettes over the internet, and $1.7 \%$ reported purchasing over the internet in the past 30 days. Nearly $9 \%$ of current smokers reported that they intended to purchase cigarettes over the internet during the next year. Logistic regression analysis was used to examine predictors of internet purchasing among current smokers. Youth who were refused the sale of cigarettes in the past 30 days were more than three times more likely to purchase cigarettes over the internet than youth who successfully bought cigarettes in the past month. The authors concluded that stronger enforcement of minors' access laws at the retail level might contribute to some youth turning to the internet as a source of cigarettes.

The findings for these three studies are similar. Although internet cigarette vendors appear to take lax precautions to avoid selling to youth, few middle school or high school students reported purchasing cigarettes on the internet in the time period from 1999 to 2001. The small proportion of youth who did report purchasing online reported greater difficulty in obtaining cigarettes from retail outlets, suggesting that more youth might purchase on the internet if retail access were sufficiently restricted. The fact that relatively few youth reported buying cigarettes online is not surprising. First, retail access of tobacco to youth has still not been restricted to the point that they need to turn to the internet. Even in states and communities where a small fraction of stores in a community sell to minors, adolescent smokers are generally well informed about which stores and clerks will sell to them. ${ }^{28}{ }^{29}$ A second reason is that adolescents are "cash poor" and they generally do not purchase by the carton, which is the most common way cigarettes are sold on the internet. In the study of 88 internet cigarette vendors, only five sites (4.6\%) allowed purchase by the pack. ${ }^{8}$ A one carton minimum was required by $42.2 \%$ of vendors, two cartons by $5.7 \%$, three cartons by $14.9 \%$, four cartons by $10.3 \%$, and five cartons by $24.1 \%$. These minimum order requirements are a substantial deterrent to most youth who purchase cigarettes for their own consumption. However, these minimum price requirements would probably not deter the small number of entrepreneurial youth who purchase on the internet with intentions of selling to friends and other underage smokers at school. Another barrier of online buying for youth is the extra hassle associated with buying online versus at a local store. Youth must choose a payment method (get a money order, obtain a credit card), evade parental detection of the delivery, and wait for the cigarettes to arrive sometime over the following week. Although these barriers will discourage many youth from purchasing cigarettes on the internet, continued monitoring of the cigarette acquisition habits of youth is warranted. Regardless, efforts should also be made to pass policies that restrict youth access to tobacco on the internet before it becomes a larger problem.

\section{Policy and enforcement to prevent youth access on the internet}

Over the past decade, substantial efforts have been made to prevent youth access to tobacco products from retail outlets. $^{29-32}$ All states have passed laws mandating that customers must be at least age 18 to purchase tobacco products, and nearly all states require in-person photographic age verification at stores. ${ }^{33}$ There is enforcement of youth access laws at retail outlets by local and state authorities. ${ }^{29}{ }^{34}$ However, attempts to restrict youth access to tobacco on the internet are primitive. 
There are no federal laws in place that make it illegal for websites to sell cigarettes to children. Several individual states have prohibited internet and mail order deliveries of cigarettes to minors, including California ( $\mathrm{AB}$ 1830), Rhode Island (General Laws 11-9-13.6), and Nevada (NRS 202 Sec. 24935). ${ }^{35}$ Several state attorneys general have conducted their own sting operations and are using existing youth access and consumer protection laws to crack down on online sales to minors. ${ }^{18} 193637$

Compliance checks of internet vendors will require the development of new enforcement methods to identify websites that sell cigarettes and to bring legal action against those who sell to minors. There is no licensing of internet vendors, so enforcement officials must first identify potential vendors. This can be facilitated by gateway sites, such as www.discountcigarettes.net that lists over 100 internet vendors in one place. Searching can also be done using multiple search engines and keywords, as described earlier. ${ }^{8}$ Determining whether a vendor sells to minors is not instantaneous as it is in the retail setting. Instead, deliveries may occur weeks after ordering, which creates logistical difficulties if it is essential for a minor to be present at the time of delivery. Protocols for handling deliveries left at the doorstep by the mail courier and whether that constitutes sales to a minor need to be established. Enforcement agencies need to budget substantially more money to purchase from websites compared to having minors purchase single packs at stores. Whereas a successful purchase of a pack of Marlboro will cost \$4-6 at most retail outlets, it will cost over $\$ 25$ per carton from internet vendors. In fact, it will cost over $\$ 100$ from internet vendors that have a five carton (50 packs) minimum purchase requirement. In addition, citing online merchants is also more difficult than citing retail merchants because many online merchants do not post their physical street address on their website. If they are fined and refuse to pay, they can set up a new website address for less than $\$ 80$ per year. Finally, individual states may have difficulties enforcing their state regulations against non-compliant out-of-state vendors, which underscores the need for federal youth access regulation addressing internet sales.

Several attempts to regulate internet tobacco sales at the federal level have been made, but none have been successful to date. In 1995, the Food and Drug Administration proposed to regulate mail order and internet sales of cigarettes, but in their final regulations they withdrew this policy citing that there was little published scientific evidence on the scope of the problem of youth access to tobacco via the internet. ${ }^{38}$ Regardless, Food and Drug Administration (FDA) authority on tobacco products was overturned by the US Supreme Court in March 2000. On 22 September 1999, Congressman Martin Meehan (D-MA) proposed federal legislation to prevent illegal tobacco sales to minors on the internet as part of the Tobacco Free internet for Kids Act (H.R. 2914). This legislation has stalled in committee, as have several more recent bills that he has introduced, including the most recent one from November 2002 entitled The Tobacco Free internet for Kids Act of 2002 (H.R. 5724). If this legislation is passed, research is needed to examine its impact on the advertised and actual sales practices of internet tobacco vendors and whether it reduces youth access to tobacco. A strong enforcement mechanism needs to accompany any merchant education efforts because education coupled with enforcement has had the largest impact on reducing tobacco sales to minors at retail outlets. ${ }^{29}{ }^{31}$

\section{SMOKING CULTURE AND LIFESTYLE SITES ON THE INTERNET}

To address the role of the internet in promoting adolescent tobacco and alcohol use, the CME examined whether tobacco and alcohol related websites targeted young people using cartoons, personalities, language, music, or branded merchandise that are popular in youth culture. ${ }^{79}$ The CME reports concluded that while the alcohol companies were clearly targeting youth on the internet with cartoons and interactive games, tobacco company sites had limited branding that appealed to youth. In their 1998 analysis of 66 websites promoting tobacco use, ${ }^{39}$ the CME found that none were dedicated to national cigarette brands, and only a few were corporate sites. The corporate sites of cigarette companies did not advertise their brands or employ marketing techniques that might appeal to children. Rather, the corporate sites provided background information on the company, had a serious tone, and highlighted the company's efforts to prevent youth smoking.

The CME concluded that the sites with the greatest youth appeal are not corporate sites, but those devoted to smoking culture and lifestyle. These sites featured pictures of celebrities smoking, smoking tips, and chat rooms or discussion boards for building a pro-smoking community. Some sites warned users that they must be at least 18 to view their contents, but any child willing to lie about his or her age would have been able to access them. The CME also noted that several smoking culture and lifestyle sites provided links to pornographic websites, and some featured photographs and "smoking fetish" videos of clothed and unclothed women smoking.

One recent study examined smoking culture and lifestyle web sites listed on Yahoo!, a popular internet search catalogue. ${ }^{40}$ The purpose was to determine whether the sites were easily accessible to youth, featured age or health warnings, and mentioned specific tobacco brands. A content analysis of photographs on these sites assessed the demographics of individuals depicted and the amount of smoking and nudity in the photographs. The sample included 30 websites and all photographs on the main page or "one click" from the main page ( $n=1689$ photographs). All of the websites were accessible to youth, and none required age verification services to enter them. Cigarette brand names were mentioned in writing on 35\% of sites, and brand images (for example, a cigarette pack or advertisement) were present on $24 \%$ of sites. Only four of the 30 sites contained cartoons, and these depicted Joe Camel or The Simpsons. Five of the 30 sites mentioned "smoking fetishes" and generally featured pictures of clothed and unclothed women smoking and/or sold videos of women smoking. Stories about smoking were featured on over a third of sites. The Smoke Signals site (www.smokesigs.com) offered one of the most comprehensive archives of stories written about smoking. The site categorised the stories by the year they were written, as well as by the major story themes. Sample story themes included "Male gets girlfriend to smoke", "Smoking couple", "Young girl starts smoking", "Mother gets daughter to smoke", or "Had quit smoking but started again". Story titles included "Smoky Beginnings for a Virgin", "Like Mother, Like Daughter", and "Daria's Smoking Apprenticeship". Nearly all of the photographs (95\%) on these 30 websites depicted smoking, 92\% featured one or more women, and 7\% contained partial or full nudity. Every photograph that depicted nudity also featured smoking.

Hong and Cody ${ }^{41}$ conducted a larger content analysis study of 318 pro-tobacco websites that were identified through two internet search engines (Google and Infoseek), and a search catalogue (Yahoo!). They also coded the photographs on the sites to examine the characteristics of the human models. They reasoned that if they were similar to existing print tobacco advertisements, that white males would be portrayed as lone, rugged individuals, African Americans would be portrayed engaging in social activities, and "there would be a preponderance of young, attractive, thin females of all ethnic backgrounds" (page 9). Of their sample of 318 sites, 50.0\% were e-commerce sites, $18.6 \%$ were hobby/recreation sites, $14.5 \%$ were sex/fetish sites, $8.8 \%$ were "other", $5.7 \%$ were corporate sites, and $2.5 \%$ were smokers' rights sites. The hobby/recreation sites included references to sports (such as 
NASCAR) and the entertainment industry (such as pictures of famous actresses smoking). Depictions of tobacco products appeared on $74.8 \%$ of sites, with cigarettes appearing most often $(43.2 \%)$, followed by cigars $(34.3 \%)$, pipe tobacco $(14.8 \%)$, snuff $(5 \%)$, and chew $(4.7 \%)$. Only $3.5 \%$ of sites featured a cartoon character, such as Joe Camel, and 22.6\% featured an animal character. Human models appeared on $56.3 \%$ of sites and were least likely to appear on e-commerce sites. Male models appeared most often on corporate, smokers' rights, and recreation sites. Female models appeared most often on sex/fetish sites, and these sites also featured the highest proportion of attractive and slim female models. The authors concluded that the portrayal of male models on recreation sites was consistent with their portrayal as rugged individuals in cigarette advertisements, and that the portrayal of beautiful slim women was also similar to the portrayal of women in print cigarette ads. The majority of the images were of white individuals, which they concluded was unlike cigarette ads that feature greater racial and ethnic diversity.

The results of these two studies underscore the need for greater research and monitoring of smoking related internet content by tobacco control advocates and for the development of new strategies to counteract the glamorisation and promotion of smoking on the internet. Research is also needed to understand whether youth are seeking out this content and what impact it has upon those youth who view it. A study of 15-16 year olds in England ${ }^{42}$ is one of the only published studies that has examined youth exposure to internet sites for cigarettes or smoking. Far fewer respondents in that study were aware of internet content when compared with more traditional tobacco marketing appearing in magazines, retail outlets, or billboards. Exposure to smoking related internet sites was reported by $4 \%$ of non-smokers and current smokers, as well as by $8 \%$ of those who had ever tried smoking. The type of the website (internet cigarette vendor, recreation, smoking glamour) that the youth viewed was not specified. It will be helpful to conduct more detailed studies of youth exposure to tobacco related internet content in the future and to understand the impact of this exposure.

Cigarette advertising serves to increase youth perceptions of the pervasiveness, image, and function of smoking, ${ }^{43}$ which have been related to increased uptake and maintenance of smoking among adolescents. ${ }^{43-47}$ Obviously, these smoking culture and lifestyle websites are not advertisements; however, they may share some of the same functions of advertising by glamorising and promoting smoking. Thus, these websites may encourage youth tobacco use even without the advertising of specific brands. Even if the tobacco companies continue to avoid placing advertising on their corporate websites, their marketing efforts may benefit from a cadre of smoking enthusiasts who promote their favourite brands through images and stories on the internet.

\section{Smoking related movie and entertainment websites}

Given the growing literature on portrayals of smoking in movies $^{48}$ and its impact on promoting the uptake of youth smoking ${ }^{49-51}$ the promotion of smoking in the movies on the internet is particularly disturbing. There is a comprehensive list of famous celebrity smokers that appears on the pro- and anti-smoking portal Smoking from All Sides (http:// smokingsides.com). The site provides detailed information on female celebrities, and documents whether they smoke in movies and "IRL" (in real life). The massive list features smoking information on hundreds of female celebrities from A (for example, Aaliyah, Christina Aguilera, Jessica Alba) to Z (for example, Moon Zappa, Renee Zellweger, Catherine Zeta-Jones). The amount and quality of smoking in movies featuring these actresses is reviewed in painstaking detail, and the movie titles feature smoking related notations, such as $\mathrm{C}$ "cigarette", G "ciGar", M "More (brand) cigarettes", and ND "no drag, holding or unlit". Movies rated "*" are highly rated because they feature "many smoking scenes" and movies with "**" are considered "smoking classics $->$ lots of scenes and drags, gorgeous actress(es)".

For instance, the entry for actress Alicia Silverstone mentions that she appeared in popular teen movies such as Clueless, The Crush, and Excess Baggage. There are excerpts from online chats and TV interviews where she discusses whether her smoking in these movies is sending the wrong message to her teen viewers. There are quotes given as "proof" that she smokes in real life, such as a quote from fellow actress Kate Winslet talking about her at the Golden Globes: "We ended up sneaking off to the rest room for a quick cigarette." The quote is even backed up with a reference "Cosmopolitan Magazine, Oct. '96, p. 184". There are also hundreds of photos depicting the various actresses smoking that have been culled from movie stills and magazine interviews.

The website www.smokingcelebs.com lists the top 25 smoking movies. The movie Grease made the list because "This movie made smoking a focal point of being sexy". In Risky Business, actress "Rebecca DeMornay definitely knows how to smoke". In Strange Days, "Juliette Lewis is very sexy smoking here, with smoke rings and one nude smoking scene". Finally, Basic Instinct makes the cut because of the infamous scene with Sharon Stone where she says, "What are they going to do, arrest me for smoking?". Smoking Celebs even has a "Teen Celeb Index" for "females who are smoking as teenagers" —it can be found at http://www.smokingcelebs.com/teenceleb.html. The dozen or more websites dedicated to smoking by celebrities are complemented by online clubs, such as the Yahoo! club "Smoking_Girls_in_Movies" or the newsgroup alt.smokers. glamour.

\section{Teen smoking web pages and clubs}

A number of teen smoking pages have been launched that claim to have been created by teens. One of the first such sites was the Jenny Teen Smoking Page, a website that was ostensibly created by a teen girl in San Francisco. The site is now defunct, but was quite popular when it was active in 1998 and 1999, and is still referenced in newsgroups today. The front page of the website mentions that Jenny, the site creator, was a 17 year old girl who had been smoking since age 13. She began smoking when she was told it would make her look sexier. Her reason for developing this website was "because I think smoking is sexy and I hate all the anti-smoking bullshit I get". Stories supposedly written by other teens were solicited for this site. Stories were often personal accounts of smoking or short stories that described topics ranging from initiation of smoking, standing up for smokers' rights, and how smoking helps attract potential boyfriends. Below are some of the verbatim quotes from stories featured on the Jenny teen smoking website:

"My sister, Kristie, is fourteen. We're real close, and she has always been so nice to me. Kristie decided to start smoking when she was barely thirteen. You can't imagine how proud I was of her the first time I watched her smoke a cigarette! It was like she became a grown-up overnight."

"My sister is so beautiful, and smoking really called attention to her gorgeous face. And she has such long, beautiful, slender fingers. Kristie looked so sexy with a cigarette between her fingers, and smoke drifting up from the tip."

"I would look thru my mom's magazines for ads or for other pictures of pretty women smoking . . . I wanted to be just like them so pretty and smoking." 


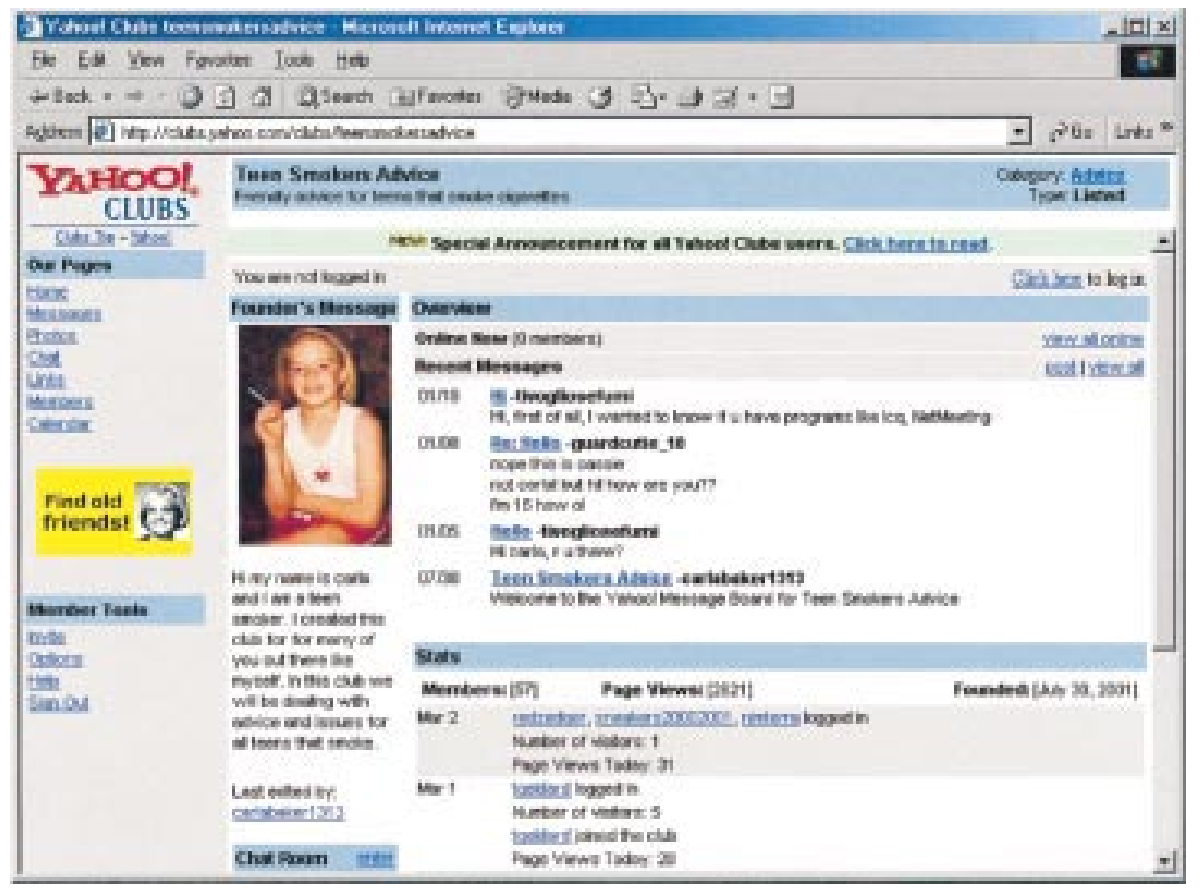

Figure 4 Example of a teen smokers club on the internet.

"He said, "I've got to say, boys are going to be paying a lot of attention to you from now on. You're beautiful, and you smoke!"

"I honestly believe that every girl in America should smoke cigarettes. More and more girls are realizing that that's true, and they are smoking at younger and younger ages. . Every day in America, more than 1,600 teenage girls smoke their first cigarettes. That's 600,000 new teenage girl smokers every year. Isn't that cool?"

"Cigarettes are inexpensive and easy to get, and it's easy to learn how to smoke. For the price of a candy bar, a girl can smoke seven or eight cigarettes, feel really good, and not get fat.

Obviously, the portrayals of smoking featured on this website glamorised smoking and touted the "benefits" of smoking to help young girls stay thin, attract the attention of boys, and appear grown up. If viewed by large numbers of teenage girls, this content could potentially have a profound impact on their smoking behaviour. How teens interpret the content needs to be investigated. Do girls believe that this was written by and for other teen girls? Do they believe the outrageous claims made about the benefits of smoking? The website home page mentioned that there is "controversy" about whether this website was created by tobacco companies. Many of the themes mentioned in these stories are similar to those featured in cigarette company advertising; however, efforts to link this website to the tobacco industry have proved fruitless.

A large number of similar websites and teen smoking clubs exist. There is the Teen Smokers Home Page (http:// members.tripod.com/teensmokers/) described as a place for "teen smokers to hang out". Viewers can see pictures of male and female teens smoking and participate in online polls or message boards. The website D.R. Humo's World of Smoking Glamour even has an online tutorial on "How to start smoking: a guide for women" (http://www.geocities.com/NapaValley/ 5097/how.html). Entries on the "course syllabus" include "Choosing your brand", "Setting the mood", and "Your first full day as a smoker." Figure 4 shows the Yahoo! Club called Teen Smokers Advice that offers "friendly advice for teens that smoke cigarettes". Other Yahoo! clubs include badteengirlssmokingden (1467 members) that tells viewers: "if u are a bad girl, u like smoking at school behind the bike sheds, in the toilets etc., and being really bad - bunking off, bullying and going on the rob join my girl gang . . it's cool to be bad." A similar club, Bad_Teen_Girls, is for the "girl who loves bullying, stealing, smoking where prohibited, getting drunk, or doing any other bad thing that's rule-breaking, then you're at the right place". The club Smoking Beauties is for the "beautiful smoking women lovers (Only Cigarettes), no old, fat \& uggly $\{$ sic $\}$ women, no fakes, just beautiful ones !!!!!!! Just the CREAM !!!!!!!!".

The internet has created a new virtual world that is readily accessible to youth where smoking is the norm, scores of attractive movie stars are lighting up, virtual teen smoking clubs abound, and detailed stories instruct would-be smokers on the finer points of smoking. For youth who smoke or are curious about the habit, this virtual world may provide a welcome refuge from the real world where parents and health officials frown upon smoking and rules hinder underage youth from buying cigarettes or from smoking them on school grounds. Unfortunately, counteracting the pro-smoking environment on the internet is in its infancy. In fact, there has been almost no attention focused on countering the smoking lifestyle and culture sites previously described. Rather, most of the internet based grassroots advocacy and countermarketing efforts described in the next section have focused primarily on traditional tobacco control strategies that have been adapted for and delivered via the internet.

\section{GRASSROOTS ADVOCACY AND COUNTERMARKETING ON THE INTERNET www.DontPardonBigTobacco.org}

The Campaign for Tobacco Free Kids (Campaign) launched an innovative online petition campaign to put political pressure on the Bush Administration to continue the US Department of Justice Lawsuit against the major tobacco companies. ${ }^{52}$ The Campaign established a "microsite" on this topic with the URL of www.DontPardonBigTobacco.org. The goals of this effort were to generate enough citizen pressure to force the administration into adequately funding the lawsuit and to build a 
base of e-activists who could take political action in the future. The website allows visitors to sign up and send a free postcard to the Bush Administration and to send a message to their friends about the site. In the first six months, this campaign generated over 30000 faxes to President Bush. This effort, along with the offline efforts of the Campaign and other groups, may have contributed to the Bush Administration support of the lawsuit against the tobacco companies.

By capturing information on the address of visitors to the site, the Campaign was able to build a large database of e-activists. Moreover, it could target information to individuals in particular states. For instance, information on special campaigns for Florida and Ohio were sent to individuals from those states. The Campaign continues to build its lists through paid banner advertising and partnerships with other internet sites. It also keeps in regular contact via email with individuals who have participated in one of its online advocacy efforts. Technically speaking, this excellent example of online grassroots advocacy goes well beyond addressing youth tobacco use, the stated focus of this paper. This example was chosen because of its applicability to youth tobacco issues, and because of the paucity of other examples of online advocacy in the scientific literature.

\section{www.thetruth.com}

The American Legacy Foundation is using multiple marketing strategies to promote its teen focused website www.thetruth.com. The website address or URL is advertised in traditional offline media channels such as television spots, tie-ins with radio stations, printed materials, and magazine advertising (for example, Spin, Seventeen, Skateboarder) and at events held at malls, rock concerts, and water parks. The site also features superstitial advertising on websites popular among teens such as www.gurl.com, www.bolt.com, and www.wwf.com. Superstitial advertisements load behind the window of the main site and, once loaded, they pop up as a full page for the viewer. Over $10 \%$ of viewers have visited the truth site through one of these Superstitial ads (Scott Dubow, personal communication, 9 January 2001). Rather than spending a lot of energy and resources trying to draw teens to the site, the American Legacy Foundation has carefully partnered with sites that are already popular among their target audience of teens. Gurl.com, for instance, receives over 60 million page views per month and has over 800000 unique viewers per month, who spend an average of 43 minutes on the site per session. These are impressive statistics compared to the worldwide average for June 2002 of about 47 seconds per web page, according to Nielsen (http://www.nielsennetratings.com/hot_off_the_net.jsp).

Another internet marketing approach used by the corporate world that could be employed for internet social marketing is viral marketing, which aims to promote the rapid adoption of a product or service through word-of-mouth networks. The term "viral" is used to denote that the message spreads contagiously from person to person. For instance, rather than solely creating an acne website, Johnson \& Johnson established a presence in online teen communities by allowing girls to send each other digital postcards offering free skin analyses and product samples. These friend-to-friend referrals allowed the message to multiply exponentially with little added cost. ${ }^{53}$ The key is to find something of interest to teens that they would like to share with their online friends. Thetruth.com features a provocative digital postcard with a urinal that reads "YOUR PEE CONTAINS UREA. Thanks to the tobacco companies, so do cigarettes. Enjoy". There is a link at the bottom so teens can send the email postcard to a friend. Many teens enjoy viewing the content of such sites and will pass along information about interesting websites to their friends. The number of times that teens send each other these digital postcards should be addressed as part of a broader evaluation of the impact the impact the truth.com website.

\section{CHALLENGES POSED BY PRO-TOBACCO FORCES} ON THE INTERNET

There are many unique challenges to tobacco control on the internet, and four of these are described below.

\section{Monitoring abundant and hidden content}

In late 1997, there were approximately 320 million web pages. $^{54}$ In 1999, there were approximately 800 million web pages. ${ }^{55}$ As of 1 February 2003, the search engine Google indexed over three billion web pages. With so much available content, it is difficult for researchers, tobacco control advocates, and parents to keep abreast of what is online. Tobacco control advocates have generally responded quickly to address the readily visible factors that promote youth smoking in the print media and movies. For example, parents and other adults took notice when they and their children were bombarded with images of Joe Camel, frequent smoking in movies, or ubiquitous ads on billboards. However, internet content can easily reach particular audiences, such as teenagers, without being seen by parents and other adults. ${ }^{39}$ Because this pro-smoking internet content does not bombard most adults in the way that cigarette advertising had in the past, many tobacco control researchers and advocates are completely unaware of how smoking is being glamorised on the internet. Monitoring trends in how smoking and tobacco use is portrayed online will be essential, and strategies for addressing it will need to be communicated with tobacco control advocates.

\section{The challenge of "sticky" content}

Another challenge is that websites and chat rooms are far more interactive than the venues in which cigarettes have traditionally been promoted, such as print advertising. That is, a viewer would probably spend far more time browsing and interacting with a pro-smoking website than viewing a static cigarette advertisement in a magazine. As a result, website viewers might receive a greater "dose" of pro-smoking content. Thus, prevention advocates must develop effective counteradvertising, which is equally engaging and goes well beyond placing traditional smoking prevention curricula online.

\section{Filtering and blocking}

For those who put faith in technological solutions such as filtering and blocking programs, the CME concluded in 1999 that they failed to screen out website content that promotes alcohol and tobacco use. ${ }^{56} \mathrm{~A}$ more recent test of four programs that explicitly included tobacco as a category for blocking found that they blocked an average of only 33.9\% of pro-tobacco websites (range 10.1-65.0\%). ${ }^{57}$ Studies of households with internet access show that most parents of children between 11-15 years old say they allow their kids to go online whenever they want, and only $5 \%$ of parents with children 16 and older say they do any monitoring of the kids' online activities. Furthermore, one study found that only $20 \%$ of parents use filtering and blocking software. ${ }^{58}$ Until filtering and blocking software programs are more effective and widely adopted by parents, their utility for counteracting websites promoting tobacco use will be limited.

\section{Regulating the internet}

Although an early version of the Master Settlement Agreement between the tobacco companies and the state attorneys general would have regulated internet content, ${ }^{59}$ the final version made no provisions regarding the internet. That said, it is notoriously difficult to regulate the internet. The United States Internet Council ${ }^{60}$ has noted that most approaches to regulating inappropriate internet content have generally failed because: 

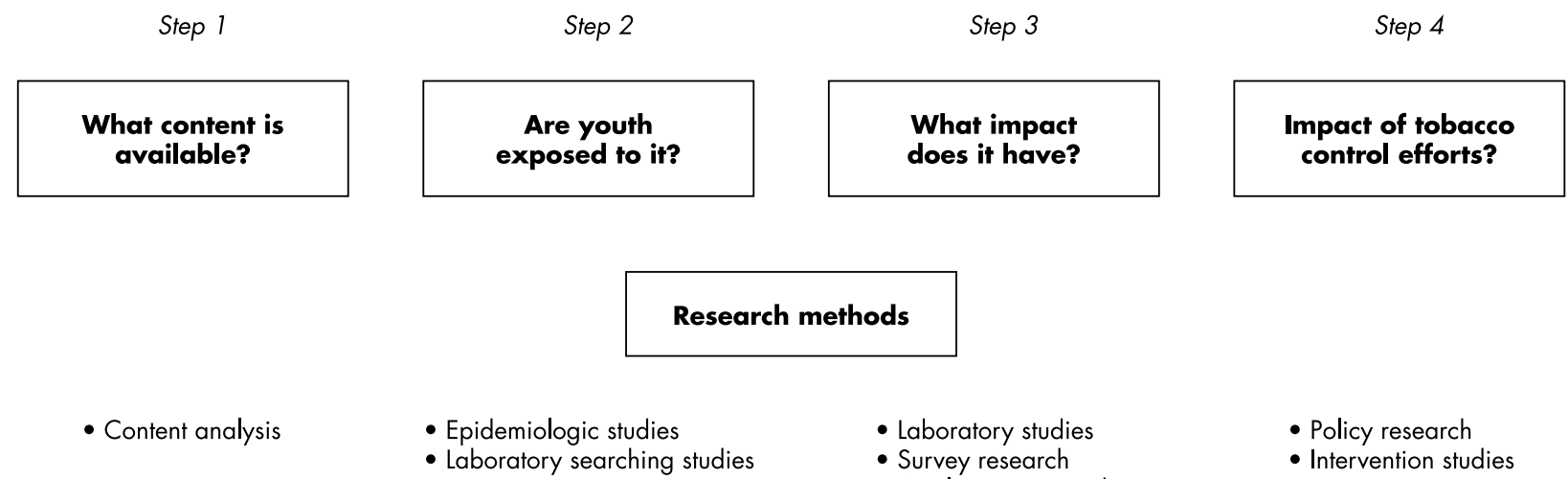

- Laboratory searching studies

Figure 5 Research agenda for tobacco related content on the internet.

" . . .the internet undermines regulatory governance by its very nature-its constant change renders out-of-date many regulations before they are fully promulgated; its international scope enables regulated parties who wish to avoid regulation to move off-shore easily; its enormous content, and effective anonymity, makes effective policing difficult." (page 21)

Aside from the logistical difficulties, there is also some ambiguity as to which government agencies would have jurisdiction over tobacco related content on the internet (for example, Federal Communications Commission, Federal Trade Commission, or FDA) and whether cigarette advertising that is banned in broadcast media, such as television and radio, would also be prohibited on the internet. ${ }^{59}{ }^{61}{ }^{62}$ However, even if US courts ruled that internet tobacco advertising is prohibited, there is a loophole. Tobacco companies with overseas subsidiaries can create websites in other countries without such regulations and these sites would still be accessible to US consumers. ${ }^{63}{ }^{64}$ This underscores the need for global regulation that transcends the laws of individual countries, such as that proposed in the Global Framework Convention on Tobacco Control. ${ }^{65}$

As mentioned earlier, cigarette advertising and content that promotes smoking often appear on the web pages of individuals who claim not to be affiliated with tobacco companies. For instance, there is a website featuring hundreds of fake cigarette ads for a fictitious brand called Foxy cigarettes (http://www.fortunecity.com/victorian/portrait/1202/

index.htm). Many of the ads feature scantily clad women and a few even feature nudity. A typical caption reads: "Foxy Slim 100's: The same tar, yet double the nicotine for the absolute maximum in smoking pleasure!" This example clearly points out one of the major challenges with the internet. Rather than trying to monitor the activities of fewer than a dozen major tobacco companies, there are hundreds, if not thousands of websites promoting tobacco use. Some are even touting cigarette brands that do not exist. Thus, regulation aimed solely at curtailing cigarette advertising on tobacco company websites would not effectively reduce youth exposure to pro-smoking content on the internet. Banning smoking lifestyle and culture sites altogether is not legally feasible, and would certainly create a backlash within the pro-smoking internet community. It will probably be more feasible to regulate internet cigarette sales because it is generally easier to regulate internet sites that advertise and ship a tangible product (for example, alcohol, cigarettes) than sites that deal with purely digital content (for example, pornography, online gambling). There is a pressing need for legal scholars to study the complicated legal and regulatory issues surrounding internet content related to tobacco to help guide appropriate policy options.

\section{RESEARCH AGENDA}

Availability and impact of tobacco related content

Research on understanding tobacco related internet content is still in its infancy. A proposed research agenda for understanding how the internet affects youth tobacco use is shown in fig 5 . The first step is to understand better the nature of tobacco related internet content that is available. This refers to content that promotes, as well as discourages, youth tobacco use. Several content analysis studies have already been conducted of cigar websites, ${ }^{12}$ internet cigarette vendors, ${ }^{68}$ smoking lifestyle and culture websites, ${ }^{40}$ and pro-tobacco websites. ${ }^{41}$ Longitudinal studies are needed to continue to monitor the proliferation of these pro-tobacco websites. Future studies should also expand on these early studies by examining content and communication occurring in chat rooms, electronic lists, and internet newsgroups for teen smokers, similar to studies on communication within internet based groups for problem drinkers, ${ }^{66}$ parents of sick children, ${ }^{67}$ and even librarians. ${ }^{68}$ In addition, there are dozens of smokers' rights websites, such as www.forces.org, and tobacco company websites that should also be studied.

Very little research has been conducted on tobacco use prevention and control websites. Moreover, tobacco control advocates' use of electronic resources (for example, GLOBALink, SCARCNet) certainly deserves study. Process measures, such as message traffic, can be readily studied, although it is unlikely that their overall "efficacy can be precisely

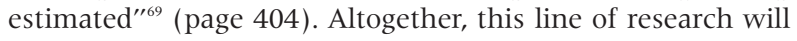
help tobacco control advocates and researchers understand the nature of communication that occurs in these electronic environments.

The second step in the research agenda is to examine the extent to which youth are exposed to tobacco related content on the internet. As mentioned earlier, there are very few studies on this topic. One study examined youth exposure to tobacco marketing ${ }^{42}$ and included questions about tobacco related content on the internet. Three studies have examined whether youth have purchased cigarettes on the internet. $^{22} 26_{27}$ Even basic research studies are needed that describe whether internet access and viewing habits of youth tobacco users differ from non-tobacco users. Perhaps few youth are ever exposed to smoking lifestyle and culture websites, which would suggest that little should be done to counteract these sites. In contrast, the impact of viewing these sites might eventually be on par with the impact of cigarette advertising or exposure to smoking in movies. These questions and others have yet to be answered, and need to be explored in future studies. Understanding how youth navigate the internet should be examined to understand better ways to reach youth with tobacco control efforts. Research is needed to learn whether youth are currently being exposed to tobacco use prevention websites, and whether these sites are having 


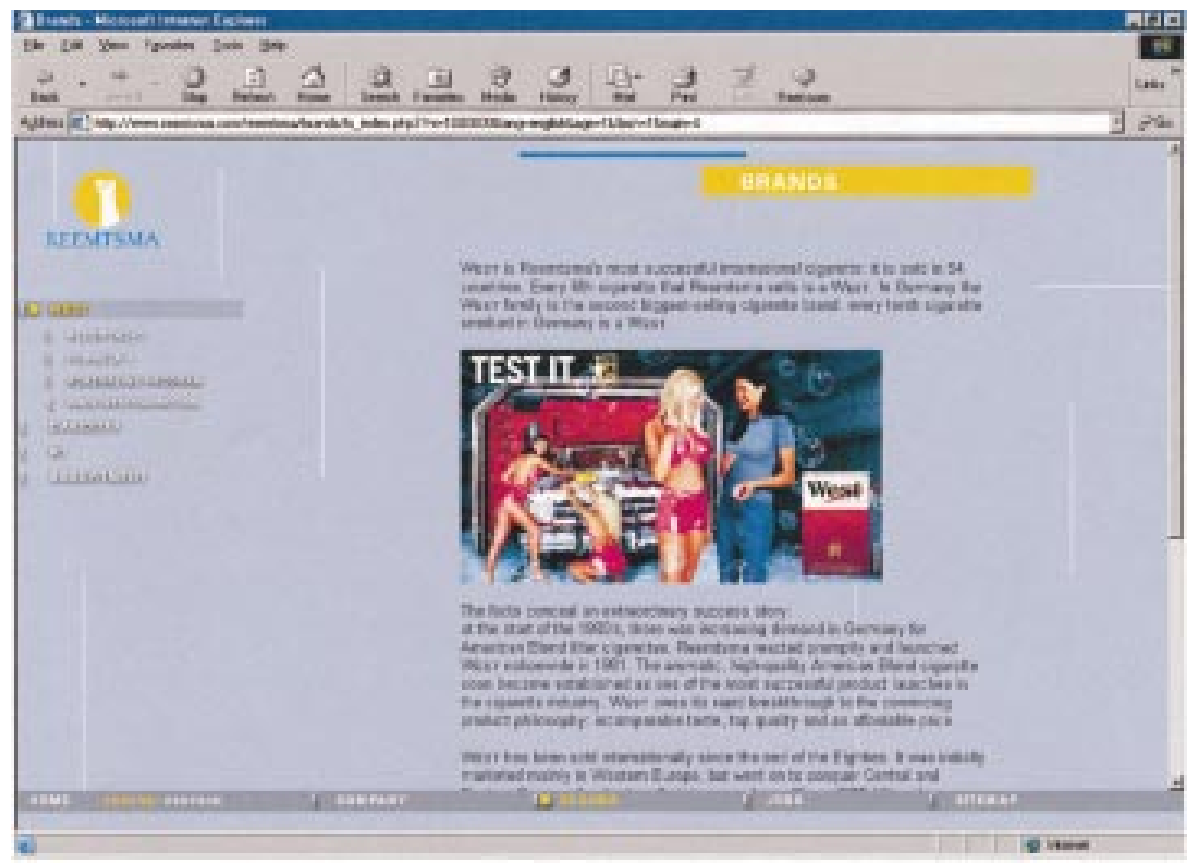

Figure 6 Tobacco company website for Reemsta.

an impact. The Kaiser Family Foundation recently completed a study of how teens and young adults (ages 15-24) use the internet as a health resource..$^{70}$ Interestingly, $90 \%$ of respondents had been online, and $75 \%$ of these online youth had searched the internet for health information. The leading health related use of the internet was for information on chronic diseases like cancer or diabetes ( $50 \%$ of online youth) and sexual health information (44\%). Information on smoking was sought by $19 \%$ of teens. This suggests that youth would be receptive to content related to tobacco control.

Very little research has been conducted on the final two steps of the proposed research agenda. Little is known about the actual impact the internet is having upon encouraging or discouraging youth smoking. This can be understood in part by conducting controlled laboratory studies, survey research, and aggregating the findings of multiple studies on these topics. The last step is to synthesise the findings on uses and impact of the internet to develop and evaluate state-of-the art tobacco control efforts. Surprisingly, there are virtually no published studies that have evaluated the impact of theory based, internet delivered tobacco use prevention programmes for youth. There is a strong need to develop such interventions, and to adapt existing programmes for an online environment.

Altogether, it appears that the existing literature is starting to answer the question posed in step 1 about what content is available. A useful comparison might be to examine the state of the literature on tobacco use in movies. Several studies have focused on portrayals of tobacco use in films, ${ }^{48} 7172$ whether youth have been exposed to the content, and how it is related to their tobacco use. ${ }^{49-51} 73$ Understanding how tobacco related internet content is similar to and different from portrayals of tobacco use in movies seems warranted. Certainly far more youth are exposed to depictions of tobacco use in movies than on the internet, but the impact of the internet is growing and youth are spending more time online each year.

\section{Monitoring tobacco companies online}

Another area needing further study is how tobacco companies are using the internet. Tobacco companies have dominated all media (for example, radio, television, magazines, point-ofsale, motion pictures) in the past and will likely turn their attention to the internet. It will be necessary to study both the overt and the covert activities of the tobacco industry. According to the Federal Trade Commission reports on tobacco mar- keting and promotional expenditures ${ }^{74}$ the tobacco companies spent $\$ 949000$ on the internet in 2000. This is a miniscule fraction of their $\$ 9.57$ billion in total advertising and marketing spending for 2000. Little is known about how this money was spent. For instance, was it spent on the development and maintenance of their corporate websites or on email outreach to smokers in their online databases? Tobacco control advocates should critically evaluate the content and claims on the websites of the major tobacco companies. None of the major US tobacco manufacturers feature advertising or promotional materials on their corporate websites; however, the German company Reemmtsa has a website (www.reemtsma.com) that promotes their brands such as West, Davidoff, and Rl (fig 6). US based RJ Reynolds recently created an online community for smokers of its Doral brand at www.smokerswelcome.com. The website describes itself as "The One and Only Online Community By and For Smokers." RJ Reynolds is supporting the effort through reduced prices on a computer and internet access for smokers (see www.ecrmguide.com/news/article/0,,10382_946491,00.html). Continued efforts to monitor these activities are needed.

In addition to tracking the overt activities of the industry, advocates must also follow the covert activities of tobacco companies. British American Tobacco (BAT) apparently spent several million dollars to build a website code named Horeca aimed at young people worldwide. ${ }^{75}$ The aim was to promote Lucky Strike and State Express 555 to young smokers who are looking for bars, clubs, and restaurants. These establishments sold, gave away, and aggressively promoted the brands. A prototype website named City Gorilla had been tested in Poland and Belgium. According to a leaked internal memo, the goal was to attract over 600000 unique visitors to the site. A countermarketing site that exposed this issue was established at www.citygorilla.org by Action on Smoking and Health. Brown and Williamson, an American subsidiary of BAT, launched a similar stealth campaign in the USA for its Lucky Strike brand as part of its "Circuit Breaker" and "Lucky Nights" campaign.$^{76}$ This and other examples underscore the need for advocates to remain vigilant. In addition, it may be fruitful to examine tobacco industry documents, especially the more recent ones that are being added to archives, to understand how the tobacco companies are planning to utilise the internet. 


\section{CONCLUSION}

The internet presents many new opportunities and challenges for tobacco control advocates. Understanding the impact of the internet on affecting youth smoking is in its infancy, as are efforts to use the internet to prevent youth smoking. This review paper raises more questions than it answers, but hopefully it will stimulate a dialogue on efforts to study and counteract burgeoning pro-smoking content on the internet.

\section{ACKNOWLEDGEMENTS}

The author would like to thank the following individuals for reviewing earlier drafts of this paper and providing helpful feedback: Suchi Ayala, Ellen Feighery, Annice Kim, Ken Warner, and two anonymous reviewers.

\section{REFERENCES}

1 US Department of Commerce. A nation online: How Americans are expanding their use of the internet. Washington DC, February 2002.

2 National Center for Education Statistics. Internet access in U.S. public school and classrooms: 1994-2000. Washington DC: US Printing Office, May 2001

3 Barton J. Tobacco on the web: even for a traditional business such as tobacco, the Internet offers tremendous opportunities. Tobacco Reporter, December 2000:62-5.

4 Mermelstein R. Teen smoking cessation. Tobacco Control 2003;12(suppl I):25-30.

5 Cohen JE, Sarabia V, Ashley M. Tobacco commerce on the internet: a threat to comprehensive tobacco control. Tobacco Control 2001:10:364-7.

6 RibisI KM, Kim AE, Williams RS. Are the sales practices of Internet cigarette vendors good enough to prevent sales to minors? Am J Public Health 2002;92:940-1.

7 Center for Media Education. Alcohol and tobacco on the web: new threats to youth. Washington DC: Center for Media Education, March 1997.

8 RibisI KM, Kim AE, Williams RS. Web sites selling cigarettes: how many are there in the USA and what are their sales practices? Tobacco Control $2001 ; 10: 352-9$

9 Armstrong L. All of the tar and none of the taxes. BusinessWeek, 7 December 1999

10 Howe K. Price rise puts heat on smokers: run on cigarette sales and Internet vendors. San Francisco Chronicle 27 November 1998;A1, A10-1

11 Price J. Cigarette tax hikes help web outlets' sales: lax enforcement helps merchants, buyers. Raleigh News \& Observer 16 September 2002;1A, $8 \mathrm{~A}$.

12 Malone RE, Bero LA. Cigars, youth, and the Internet link. Am J Public Health 2000:90:790-2.

13 Jenkins Act. U.S. Code, Title 15 (Commerce and Trade), Chapter 10A (Collection of state cigarette taxes) Sections 375-8.

14 General Accounting Office. Internet cigarette sales: giving ATF investigative authority may improve reporting and enforcement. Washington DC, August 2002

15 Emery S, White MM, Gilpin EA, et al. Was there significant tax evasion after the 199950 cent per pack cigarette tax increase in California? Tobacco Control 2002;11:130-4.

16 Cheskin Research and Cyberteens.com. Teens and the future of the web. Redwood Shores, California, August 1999

17 Associated Press. Michigan cracks down on on-line cigarette sales. The Globe and Mail 28 September 2000

18 Noack D. Sting targets online cigarette sales from India. APBnews.com 28 December 1999.

19 Scherer R. States crack down on web tobacco sales. The Christian Science Monitor 8 November 2000.

20 Tobacco Law Project. Smoke on the web: can children buy cigarettes online? Saint Paul, Minnesota: William Mitchell College of Law, March 2002

21 RibisI KM, Williams RS, Kim AE. Do internet cigarette vendors sell to minors? Results of a purchase survey. Under review.

22 Centers for Disease Control and Prevention. Youth tobacco surveillance, United States, 2000. MMWR Morb Mortal Wkly Rep 2001; 50(SS-4): 1-84

23 United States Internet Council \& ITTA Inc. State of the internet 2000 Washington DC: 1 September 2000.

24 Krochmal M. Younger buyers will affect online commerce. Techweb Technology News 29 September 1999.

25 Office of Applied Studies. How youths get cigarettes: the NHSDA report. Rockville, Maryland: Substance Abuse and Mental Health Services Administration, 22 November 2002

26 Unger JB, Rohrbach LA, Ribisl KM. Are adolescents attempting to buy cigarettes on the Internet? Tobacco Control 2001;10:360-3.

27 Abrams SM, Hyland A, Cummings KM. Internet purchase of cigarettes among 9th grade students in western New York. Prev Med (in press).

28 Difranza JR, Coleman M. Sources of tobacco for youths in communities with strong enforcement of youth access laws. Tobacco Control $2001 ; 10: 323-8$

29 Forster JL, Wolfson M. Youth access to tobacco: policies and politics. Annu Rev Public Health 1998;19:203-35.
30 DiFranza JR, Celebucki CC, Seo HG. A model for the efficient and effective enforcement of tobacco sales laws. Am J Public Health 1998;88:1100-1.

31 Feighery E, Altman DG, Shaffer $G$. The effects of combining education and enforcement to reduce tobacco sales to minors: a study of four Northern California communities. JAMA 1991;266:3168-71.

32 Jason LA, Ji PY, Anes MD, et al. Active enforcement of cigarette control aws in the prevention of cigarette sales to minors. JAMA 1991;266:3159-61.

33 Fishman JA, Allison $\mathrm{H}$, Knowles SB, et al. State laws on tobacco control - United States, 1998. MMWR Morb Mortal Wkly Rep 1999:48(SSO3):21-62

34 Howard KA, Ribisl KM, Howard-Pitney B, et al. What factors are associated with local enforcement of laws banning illegal tobacco sales to minors? A study of 182 law enforcement agencies in California. Prev Med 2001;33(2):1-8

35 Lindblom E. Elements of model state Internet legislation to prevent evasion of state tobacco-product excise taxes and to block youth access. Washington DC: Campaign for Tobacco Free Kids, 17 November 2002

36 Associated Press. Tax-free cigarette sales over Net probed. Bergen Record Corp 14 April 1998. URL: www.bergen.com/news/ notax 199804147.htm

37 Johnson SM. Dirtcheapcig.com smoked in sting. LocalBusiness.com 20 September 2000

38 Department of Health and Human Services. Regulations restricting the sale and distribution of cigarettes and smokeless tobacco products to protect children and adolescents; Final Rule. Federal Register 1996:61:44396-618

39 Center for Media Education. Tobacco targeted at youth on the internet: an update. Washington DC: Center for Media Education, 1998

40 RibisI KM, Lee RE, Henriksen L, et al. A content analysis of web sites promoting smoking culture and lifestyle. Health Educ Behav 2003:30:64-78.

41 Hong T, Cody M. Presence of pro-tobacco messages on the Web. J Health Comm 2002;7:273-307.

42 MacFadyen L, Hastings G, MacKintosh AM. Cross sectional study of young people's awareness of and involvement with tobacco marketing BM 2001:322:513-7.

43 US Department of Health and Human Services. Preventing tobacco use among young people. A report of the Surgeon General, 1994 Atlanta, Georgia: Public Health Service, Centers for Disease Control and Prevention, Office on Smoking and Health, 1994. (US Government Printing Office Publication No S/N 017-001-00491-0.)

44 Aitken PP, Eadie DR, Hastings GB, et al. Predisposing effects of cigarette advertising on children's intentions to smoke when older. Br J Addiction $1991 ; 86: 383-90$

45 Gilpin EA, Pierce JP. Trends in adolescent smoking initiation in the United States: is tobacco marketing an influence? Tobacco Control 1997:6:122-7.

46 Pierce JP, Gilpin E, Burns DM, et al. Does tobacco advertising target young people to start smoking? Evidence from California. JAMA 1991;266:3154-8.

47 Pierce JP, Gilpin EA. A historical analysis of tobacco marketing and the uptake of smoking by youth in the United States: 1890-1977. Health Psychol 1995; 14:500-8.

48 Stockwell TF, Glantz SA. Tobacco use is increasing in popular films. Tobacco Control 1997;6:282-4

49 Sargent JD, Beach ML, Dalton MA, et al. Effect of seeing tobacco use in films on trying smoking among adolescents: cross sectional study. BM 2001:323:1394-7.

50 Tickle JJ, Sargent JD, Dalton MA, et al. Favourite movie stars, their tobacco use in contemporary movies, and its association with adolescen smoking. Tobacco Control 2001;10:16-22.

$51 \mathrm{McCool}$ JP, Cameron LD, Petrie KJ. Adolescent perceptions of smoking imagery in film. Soc Sci Med 2001;52:1577-87.

52 Hedrick C. DontPardonBigTobacco.org (Draft Case Study). Washington DC: Campaign for Tobacco Free Kids, 2001.

53 Kenny D, Marshall JF. Contextual marketing: the real business of the Internet. Harvard Business Review, November-December 2000: 1 19-25.

54 Lawrence S, Giles CL. Searching the world wide Web. Science 1998;280:98-100.

55 Lawrence S, Giles CL. Accessibility of information on the web. Nature 1999;400:107-9.

56 Center for Media Education. Youth access to alcohol and tobacco web marketing: the filtering and rating debate. Washington DC: Center for Media Education, 1999

57 Reagan KA, Hong T, Cohen EL, et al. Blocking access to online tobacco sales sites. Tobacco Control 2002;11:164-5.

58 Yamada M. Most older kids surf unsupervised: Access date: 30 April 1999. URL: www.CNN.com

59 Warner B. Internet marketing soon to be snuffed out. Adweek $1997 ; 7(26): 28$

60 United States Internet Council. State of the Internet: USIC's report on use and threats in 1999, 1999.

61 Scherer R. Tobacco ads: legal or not on the internet? Christian Science Monitor 1995; August 14:1

62 Nash KS. Vice sites walk a thin line. [website review] Computerworld (Company Business and Marketing) 1997;31 (23):59-61.

63 Center for Media Education. ABSOLUTe Web: Tobacco and alcohol industries launch into cyberspace. Washington DC: Center for Media Education, 1997

64 Taylor C. Smoke sites fire up overseas. Interactive Week $1996 ; 3(16): 27$ 
65 Taylor AL, Bettcher DW. WHO Framework Convention on Tobacco Control: a global "good" for public health. Bull World Health Org 2000;78:920-9

66 Klaw E, Heubsch PD, Humphreys K. Communication patterns in an on-line mutual help group for problem drinkers. J Community Psychol 2000;28:535-46.

67 Mickelson K. Seeking social support: parents in electronic support groups. In: Kiesler S, ed. Culture of the internet. Mahwah, New Jersey: Lawrence Erlbaum Associates, Inc, 1997.

68 Wildemuth BM, Crenshaw L, Jenniches W, et al. What's everybody talking about? Message functions and topics on electronic lists and newsgroups in information and library science. J Educ Library Information Sci 1997;38(2): 137-56.

69 US Department of Health and Human Services. Reducing tobacco use: a report of the Surgeon General. Atlanta, Georgia: US Department of Health and Human Services, Centers for Disease Control and

Prevention, National Center for Chronic Disease Prevention and Health Promotion, Office on Smoking and Health, 2000.
70 Kaiser Family Foundation. Generation Rx.com: How young people use the internet for health information. Menlo Park, California: Kaiser Family Foundation, 2001

71 Goldstein AO, Sobel RA, Newman GR. Tobacco and alcohol use in G-rated children's animated films. JAMA 1999;281:1131-6.

72 Roberts DF, Henriksen L, Christenson PG. Substance use in popular movies and music. Washington DC: Office of National Drug Contro Policy, April 1999.

73 Distefan JM, Gilpin EA, Sargent JD, et al. Do movie stars encourage adolescents to start smoking? Evidence from California. Prev Med 1999;28:1-11.

74 Federal Trade Commission. Report to Congress for 2000: pursuant to the Federal Cigarette Labelling and Advertising Act. Washington DC: FTC, 2002.

75 Anon. BAT's internet marketing plan. Tobacco Control 2001;10:91.

76 Ross C, Teinowitz I. Luckies strike Web with stealth tobacco site. Advertising Age 1997;68(8): 1 